\title{
LOS CUERPOS Y SUS MARCAS SOCIO-ÉTNICAS: FUTBOL, IDENTIDADES E HISTORIA EN LOS VALLES ORIENTALES DE JUJUY (ARGENTINA)
}

\author{
DR. FEDERICO FERNÁNDEZ \\ Licenciado en Antropología. FHyCS (Universidad Nacional de Jujuy-Argentina). Doctor en Ciencias \\ Sociales (Orientación Historia). FFyL (Universidad Nacional de Tucumán-Argentina). Becario \\ Posdoctoral CONICET ${ }^{1}$ (San Salvador de Jujuy - Provincia de Jujuy - Argentina) \\ E-mail: antropo428@yahoo.com.ar
}

\begin{abstract}
RESUMEN
Producto de una pesquisa etnográfica desarrollada durante cuatro años (2007-20 l 0) en los valles orientales de la Provincia de Jujuy (Argentina), este articulo tiene por objeto analizar una serie de procesos históricos de larga duración dentro de un área de estudio particular, con el propósito de establecer las coordenadas estructurales que permitieron configurar las relaciones entre: las nociones socio-históricas sobre los cuerpos, las categorizaciones socio-étnicas regionales dominantes, y las identificaciones grupales más sentidas entre los jugadores y simpatizantes del fútbol practicado entre los pueblos Vallistos.
\end{abstract}

PALABRAS CLAVES: Cuerpo; etnicidad; identidades; fútbol

I. Tanto los estudios de posgrado culminados, como así también las actividades de investigación que llevé adelante para el desarrollo de la presente investigación, han sido financiadas en su totalidad por la Comisión Nacional de Investigaciones Científicas y Técnicas (CONICET) de la Argentina. 


\section{INTRODUCCIÓN}

La provincia de Jujuy se encuentra ubicada en el extremo norte de la cartografía nacional, allí donde limitan las repúblicas de Argentina, Bolivia y Chile. Tal división geográfica comenzó a trazarse recién durante las primeras décadas del siglo XIX bajo una política-económica explícita que desencadeno en la conformación de los territorios de los estados-nacionales modernos.

A pesar de los esfuerzos deliberados por parte de los estados limítrofes por diferenciarse (programas de educación fuertemente nacionalistas, inyecciones periódicas de símbolos patrios, instalaciones permanentes de gendarmerías nacionales), el espacio liminal como el que ocupa hoy la provincia de Jujuy, puede ser caracterizado como un "bricolaje identitario" entrecruzado por miles de fragmentos que trascienden, y al mismo tiempo configuran estas tierras de fronteras históricas y dinámicamente porosas.

Una mirada general al registro arqueológico del noroeste argentino, el sur de Bolivia y el sector norte de Chile, nos permite visualizar además de las particularidades materiales propias de los grupos originarios presentes en cada una de la regiones, un sustrato de intercambio e influencias comunes mantenidas durante largos periodos temporales, incluso hasta el final de la dominación hispano-colonial. Es precisamente en este contexto de solapamientos, intercambios y tensiones entre agrupamientos aborígenes que ocuparon y ocupan un territorio mucho más diverso y complejo que el de los actuales estados-nacionales, en donde me interesa re-pensar las dinámicas categorizaciones socio-étnicas ligadas a las nociones de cuerpo construidas en el pasado, pero fuertemente seleccionadas y re-significadas en el presente.

A partir del trabajo de Frederic Barth (1976) hacia finales de la década del 60', el debate académico acerca de los componentes que conforman el término étnico, pasa de una visión estática de diferenciación de los grupos en donde se puso énfasis en los rasgos materiales (vestimentas, adornos, ajuares, territorios delimitados) y la lengua como rasgo diferenciadores entre grupos étnicos, a un análisis de mayor dinámica inter-grupal donde la relaciones entre agrupamientos que antes aparecen como "paquetes culturales" distintos entre sí, son entendidos como grupos que interactúan en espacios liminales: luchan, se desarman, se vuelven a armar y, fundamentalmente, son influenciables entre si y cambian a lo largo del tiempo.

Desde esta última perspectiva, "lo étnico" implica no ya un rótulo cultural que define a un grupo en relación a otros, sino más bien una construcción cultural cargada de historicidad y relaciones de poder, una invención política que ya no depende mecánicamente de los rasgos estéticos en términos arqueológicos, sino más bien de los sentidos otorgados por múltiples historiografías sobre los grupos, sus contactos y sus fronteras. 
En la región de los valles orientales de Jujuy, más específicamente en el actual departamento Valle Grande², las categorizaciones socio-étnicas utilizadas actualmente por la mayoría de los pobladores locales tiene como uno de sus canales privilegiados de expresión al espacio futbolístico practicado hacia dentro de la región. Durante el desarrollo del campeonato futbolístico de Valle Grande, un evento particular que logra reunir a los diez poblados rurales que conforman el área vallegrandina durante tres días al año, y en el cual sólo pueden participar como jugadores los varones nacidos dentro del distrito; se ponen "en juego" un conjunto variado de adjetivaciones de base socio-étnica centradas fundamentalmente en categorizaciones sobre los movimientos corporales de los jugadores y sus relaciones con cierta historiografía territorial. Así, por ejemplo, las percepciones y representaciones de los poblados y sus respectivos equipos de fútbol pueden dividirse básicamente en dos micro-regiones: "los de arriba", localidades que efectivamente ocupan la porción norte del departamento (entre los 2500 y 3400 metros sobre el nivel del mar) caracterizados como: "los Collas del valle" vinculados casi mecánicamente con un estilo de juego brusco, tosco e inconsistente con el manejo del balón entre los pies ; y "los de abajo" (poblados que ocupan el sector sur-este del departamento, entre los 2500 y 800 metros sobre el nivel del mar), etiquetados frecuentemente como los chaguancos ${ }^{3}$ y/o criollos vallistos, también considerados como duros y resistentes para poner el cuerpo en el juego, pero con una mayor y diferenciadora habilidad con los pies, expresado en cierto tono de "picardía en el juego".

El trabajo de investigación etnográfico ${ }^{4}$ que desarrollé durante cuatro años en la región vallegrandina sobre el fútbol y sus múltiples expresiones identitarias locales y regionales, da cuenta precisamente de las asociaciones indisolubles entre la práctica de éste deporte y una serie de características estructurales cuyas configuraciones responden a procesos socio-históricos específicos.

2. La porción sur-oriental de la provincia de Jujuy comprende actualmente los departamentos de Ledesma, San Pedro, Santa Bárbara y Valle Grande. Este último se encuentra ubicado dentro de los valles orientales de transición entre las yungas y las altas montañas o Puna, con una variación altitudinal y ecológica importante. Según los datos censales del año 200 I (INDEC) la población del departamento de Valle Grande es de 2386 habitantes con una superficie de $962 \mathrm{Km} 2$. En la actualidad existen dentro de este extenso territorio diez (I0) localidades rurales distribuidas en altitudes que van desde los 800 a 4600 metros sobre el nivel del mar (m.s.n.m) con diferentes microclimas y pisos ecológicos de ocupación.

3. El término chaguanco es una denominación fuertemente peyorativa basada en pre-juicios étnicos, y que le es generalmente aplicada a las poblaciones de origen mataguayo proveniente del chaco argentino.

4. El método etnográfico, tal y como lo he aplicado en la región de Valle Grande, implicó básicamente una serie de registros in situ con observaciones participantes, mapeo gráfico de los jugadores de fútbol durante diez $(10)$ partidos. Un total de 20 charlas informales registradas en papel. Quince (15) entrevistas en profundidad, y dos historias de vidas desarrolladas bajo un enfoque biográfico. 
En las líneas que siguen nos centraremos en una serie de aspectos socio-históricos ligados a categorizaciones corporales que atraviesan transversalmente procesos de larga duración temporal en la región vallegrandina, y cuyas bases estructurales pueden ser interpretadas en torno a las dinámicas nociones de etnicidad en la región sur-andina. Comenzaremos entonces con una caracterización general de las líneas teóricas que considero son centrales para el abordaje de los datos históricos, estableciendo los sentidos, diferencias y continuidades que existen entre un conjunto determinado de prácticas rituales que preceden al fútbol moderno, pero cuyos significados primarios parecen persistir en el tiempo. En la última parte de texto, retomaré algunos de los hilos narrativos surgidos del trabajo de campo etnográfico, en donde los actuales pobladores de Valle Grande establecen nexos simbólicos que nos remiten a las nociones de resistencia y habilidad expresadas en la práctica del fútbol contemporáneo, pero cuyas formas sociológicas e históricas de enfrentamiento posiblemente se encuentren ligadas a procesos históricos macro-regionales.

\section{HACIA UNA SOCIOLOGÍA HISTÓRICA DEL CUERPO EN EL ESPACIO SUR-ANDINO}

De acuerdo con el planteo inicial de David Le Breton (2002, p. 7) en su Sociología del cuerpo, el estudio del cuerpo: "[...] forma parte de la sociología cuyo campo de estudio es la corporeidad humana como fenómeno social y cultural, materia simbólica, objeto de representaciones y de imaginarios"

Tal extensión y diversidad temática, implica al mismo tiempo un conjunto variado de campos de investigación donde se incluyen perspectivas teóricas sobre las cuales se ha construido, en primer lugar, definiciones instrumentales sobre la corporeidad y las tramas sociales que le dan sentido en espacios culturales y socio-históricos específicos. Así pues, siguiendo el planteo de Le Breton, es posible establecer al menos tres grandes campos de investigación que al mismo tiempo se vinculan en términos generales con raíces epistémicas diferentes: los análisis dedicados a las lógicas sociales y culturales del cuerpo, edificado fundamentalmente a partir del estudio pionero de Marcel Mauss ( 1979) sobre las técnicas corporales. Un segundo campo comprendido por los estudios sobre los imaginarios sociales del cuerpo, que incluye un espacio común en donde podemos encontrar desde posturas fuertemente vinculadas a la socio-biología, hasta los trabajos de corte culturalista como los de Margaret Mead y/o las investigaciones más contemporáneas sobre gestualidades y "modelos corporales". El tercer gran campo comprende también un conjunto bastamente heterogéneo que Le Breton denomina como: "El cuerpo en el espejo de lo social". Esto es, entender el estudio del cuerpo: "[ . . . ] como objeto 
concreto de investidura colectiva, como soporte de las escenificaciones y de las semiotizaciones, como motivo de distanciamiento o de distinción a través de las prácticas y los discursos que provoca" (LE BRETON: 2002, p. 8I).

Es precisamente en este tercer campo y sus componentes teoréticos más sobresalientes donde centraré el presente análisis interpretativo, es decir, en un enfoque analítico y reflexivo (etnográfico) sobre las tramas socio-culturales que envuelven y llenan de significados sociológicos e históricos a la noción de cuerpo.

Desde esta perspectiva, y de acuerdo con la especificidad temática de la investigación, son imprescindibles el uso de categorías analíticas como la de: juego en sociedad; concepto elaborado por Simmel (2003) en Cuestiones fundamentales de sociología; y la perspectiva configuracional desarrollada originalmente por Norbert Elias para el caso específico de los orígenes y devenires socio-históricos de los deportes modernos.

Según Simmel (2003), la idea de juego en sociedad, constituye una forma de socialización que nos remite a formas primarias de interacción que conjugan al menos dos dimensiones del juego, creando la sensación de estar jugando entre iguales sin otra finalidad que la del juego mismo.

Los entramados sociológicos (modelos de juego) planteados por Norbert Elias ( I 982) en su Sociología Fundamental, pueden ser entendidos como una forma específica de aplicación de modelos normados - es decir, del jugar a "la sociedad" tal como lo ha planteado originalmente G. Simmel - tomando ejemplos de fenómenos socio-políticos como las relaciones de poder en estructuras oligárquicas y/o disputas entre grupos en un sistema democrático.

A diferencia de la gran producción intelectual centrada sobre los procesos históricos de rupturas y continuidades entre etapas históricas específicas, y sus vínculos directos con los estudios del cuerpo y la emociones en el viejo continente; existen escasos trabajos históricos, sociológicos y/o antropológicos sobre el territorio sur-andino en donde el centro analítico principal sean las tramas simbólicas, las investiduras colectivas posibles de ser leídas en y a través de los cuerpos. ¿Cuales fueron las lógicas socio-culturales, políticas y de poder sobre las cuales se estructuraron los conflictos inter-grupales (socio-étnicos) en el área sur-andina pre-hispánica? iEn que medida es posible visualizar, a través del registro arqueológico y etnohistórico regional, estas tramas culturales de tensión en los cuerpos?

\section{ELEMENTOS PARA UNA SOCIO-ANTROPOLOGÍA DEL CUERPO Y LAS NARRATIVAS SOCIO-ÉTNICAS EN LOS VALLES ORIENTALES DE JUJUY}

En la provincia de Jujuy se han encontrado evidencias arqueológicas de un cráneo preparado como trofeo, como así también otras iconografías rupestres 
que marcan el accionar bélico en regiones cercanas y vinculadas espacialmente a la Quebrada de Humahuaca (territorio ligado desde tiempos pre-hispánicos al área norte de Valle Grande).

De Feo y Fernández (1998), establecen que durante el Periodo Tardío o de Desarrollos Regionales ( 000 a |47|AD), los pobladores de Valle Grande ya se encuentran vinculados con grupos quebradeños. Según esta primera interpretación del registro arqueológico, la dinámica ocupacional conjuntamente con los recursos presentes en la zona, permiten pensar que Valle Grande se encontraba habitado por colonias especializadas en la explotación de recursos provenientes de la región de la yunga; con el objeto de abastecer a las comunidades asentadas en la zona de origen en la Quebrada de Humahuaca, y en el marco de una estrategia de control vertical de un máximo de pisos ecológicos similar al modelo desarrollado por J. Murra para los Andes.

En el sector más meridional del actual departamento Valle Grande, en cambio, se han encontrado evidencias arqueológicas de pueblos de origen chaqueño, no-andinos ${ }^{5}$.

En síntesis, el escaso registro arqueológico presente en la zona, nos permite pensar en la región vallegrandina como un espacio inter-étnico complejo, territorio liminal donde confluían grupos con acervos culturales diversos, y, bajo determinadas condiciones contextuales, en franca oposición y conflicto.

Los estudios etnohistóricos sobre la región parecen confirmar esta idea de "pasillo étnico múltiple" que habría abarcado todos los valles orientales de Jujuy. Se han reconocido básicamente la presencia y co-existencia de grupos churumatas, ocloyas y mataguayos (provenientes del chaco).

Es posible que hayan existido diversas formas de interacción entre éstos pueblos; el enfrentamiento bélico es quizás el más conocido, pero también hubo intercambios comerciales, vínculos recíprocos de carácter asimétrico, todo esto puede haber existido sin necesidad de excluir unos y otros.

La decapitación, exhibición de la cabeza y el cuerpo del sacerdote Pedro Ortiz de Zárate en manos de grupos aborígenes chaqueños en inmediaciones de la región vallegrandina ${ }^{6}$,podría haber significado una clara evidencia de "demostración política"

5. Según la arqueóloga Mercedes Fumagalli: [... en la zona de Santa Bárbara [Valle Grande], Madrazo excavó un sitio que adscribe a pueblos de origen chaqueño en base a su patrón de asentamiento y ergología asociada; por lo tanto correspondería a otras formas de ocupación del espacio y explotación económicas; pertenecientes a etnias provenientes del Oriente (FUMAGALLI, 1995, p. 67).

6. Según el sacerdote Pedro Lozano, el asesinato y decapitación de Pedro Ortiz de Zarate y los misioneros que lo acompañaron desde Zenta (uno de los caminos de entrada a las yungas por la región norte de Valle Grande), ocurrió a finales del siglo XVIII. La caracterización que hace P. Lozano sobre este hecho es contundente en tanto define a los indios como: "traidores, incitados por el demonio y bárbaros del odio", mientras que los evangelizadores son definidos como: "ministros indefensos de Dios y mártires venerables". Sobre el móvil y las características del 
de parte de grupos étnicos enfrentados entre sí, más un tercer grupos de poder en cuestión: las fuerzas (religiosas y militares) hispano-coloniales ya instaladas en Jujuy.

Sin embargo, lo que resulta interesante de este hecho no es ya el acto de cortarle la cabeza a un emisario del "orden cristiano". Básicamente, la práctica de la decapitación en un contexto de enfrentamiento bélico y ritual, tuvo un sentido simbólico particular durante los enfrentamientos inter-étnicos en algunos pueblos andinos; y también estuvo presente como práctica ritual y guerrera en los pueblos bajos del oriente ${ }^{7}$. Aún más significativo que una cabeza en manos de aborígenes, son las adjetivaciones que los cronistas religiosos han elaborado sobre estos grupos étnicos para justificar las represarías violentas y sanguinarias contra pueblos originarios. Así pues, según el mismo sacerdote Pedro Lozano (1989), "naciones churumatas" cercanas a Jujuy, es decir, los churumatas mataguayos que Ferreiro (1994) vincula a la serranía de Zenta, conjuntamente con otros grupos de piedememonte son "Caribes", esto es:

[...] comedores de carne humana, pérfidos por extremo sin poderse fiar de su palaba; muy dados a la guerra, que levantan entre sí fácilmente, y algunos la tienen a veces con los Guaycurús, y todos de continuo con el Español, aunque respecto de éstos, más se pueden llamar ladrones que soldados, porque nunca hacen cara a los Españoles, sino que acometen a hurtadillas. (LOZANO, 1989, p. 83).

De este tipo de adjetivaciones, se deducen una serie de categorizaciones socio-étnicas sumamente negativas de parte de los españoles para con los grupos originarios que transitaban por la región vallegrandina. Se trata pues, en la versión de la evangelización temprana, de indios feroces, dados para la guerra, ladrones y, fundamentalmente, traidores para la pelea cuerpo a cuerpo. Esta secuencia de ideas es la que subyace incluso en la actualidad en una pequeña estampilla con la imagen de Pedro Ortiz de Zárate 8 .

Tal caracterización sobre el comportamiento de estos indígenas en la pluma española, se basó esencialmente en un vínculo explícito entre categorizaciones

asesinato, comparto la interpretación de J. P. Ferreiro (1997), quien entiende que la posición de poder económico y político que tenía la familia Zarate en la colonia de Jujuy es un hecho clave para comprender el asesinato. Esto es, entender la decapitación de Pedro Ortiz de Zarate en manos de aborígenes del chaco no como consecuencia de su labor apostólica, sino más bien a la manera de un "magnicidio político" en un contexto de posibles alianzas y fricciones entre los diferentes grupos étnicos presentes en la región.

7. Sobre este punto se puede consultar el trabajo pionero de Alfred Métraux (1949) "Warfare, Cannibalism, and Human Trophies".

8. En esta estampilla, el sacerdote cristiano es representado portando una cruz en su mano izquierda y, mientras mira hacia el cielo, es atacado por la espalda por un nativo que hunde su cuchillo a la altura del abdomen del sacerdote. En el mismo cuadro, en la parte superior, se visualiza la imagen de un ángel quien, al mismo tiempo que se produce el asesinato, coloca una corona de laurel en la cabeza del religioso. La oración que se encuentra al revés de ésta imagen reza: "Oración para la beatificación del Siervo de Dios Pedro Ortiz de Zarate". 
fenotípicas, corporales, y nominaciones socio-étnicas ("churumatas", "mataguayos") que han trascendido y re-significado en la historia de larga duración local y regional.

Una serie importante de cambios estructurales han acaecido desde el contexto histórico y político en el que se dio el asesinato de este sacerdote emparentado con la elite de mayor prestigio económico y político de Jujuy, hasta la "re-conversión" - dentro de la narrativa dominante local - de la imagen de ferocidad marcada en el cuerpo de los indígenas, a la de trabajadores rurales de poca monta y a destajo.

A diferencia del sistema de encomienda y de la dinámica de la ocupación de la tierra que regularon y dominaron las relaciones productivas durante los siglos $\mathrm{XVI}$, XVII y la primera parte del siglo XVIII; en el periodo I 880- I 930 se desarrollan un conjunto de mecanismos coercitivos que posibilitaron el acceso al mercado de trabajo asalariado de grandes sectores de la población indígena y campesina. La fuerza de trabajo rural, tal como lo ha definido Rutledge (1987), representa aquí el motor que dinamizó la producción de los Ingenios azucareros en las provincias de Salta y Jujuy.

Las fuerzas productivas y la acumulación se concentraron, entonces, en los valles bajos de la provincia, más específicamente en los ingenios azucareros cercanos al área que comprende al actual departamento Valle Grande. Dentro de este micro-espacio regional, se disparó un crecimiento cuantitativo de la estructura económica, construido básicamente sobre dos factores centrales: el apoyo político en las tarifas de protección destinadas al crecimiento del mercado interno del azúcar, y el progresivo reclutamiento de trabajadores estacionales, lo cual desembocó en un proceso de proletarización incompleto?.

Este último punto es de particular interés en tanto constituye, dentro de los argumentos escritos por Rutledge, un "elemento" de carácter estructural e histórico en la formación económica de Jujuy. Si bien el analista británico no hace una referencia explícita a categorizaciones socio-étnicas vinculadas al mercado de trabajo en Jujuy, es factible reconocer una equiparación entre determinados procesos de trabajo y grupos poblacionales pre-categorizados social e históricamente, teniendo como eje el cuerpo-otro-indígena ${ }^{10}$. Así por ejemplo, para Rutledge ( 1987, p. I75):

En el periodo que va de 1880 a 1930, la gran mayoría de los trabajadores empleados en la industria azucarera jujeña, eran indígenas chaqueños semi-salvajes, Matacos, Tobas, Chiriguanos y Pilagás. El grupo más importante, era el de los Matacos.

9. La proletarización incompleta, implicó básicamente un proceso mixto de dos actividades centrales. Una de ellas se vinculó con la reproducción dentro de las unidades domésticas (economía campesina) y, por otro lado, el empleo a tiempo incompleto en los ingenios azucareros.

10. La lectura e interpretación de Gabriela Karasic (2003) en su trabajo titulado: "La etnografía en el cuerpo: dominación e insumisión en las exploraciones de principios del siglo XX en Jujuy (Argentina)", constituye un análisis pionero y significativo de estos procesos de pre-categorización negativo basado en estereotipos corporales para con un sector de la población indígena de Jujuy a principios del siglo XX. 
La marcada segmentación de los proceso de trabajo dentro de la producción azucarera jujeña, se basó, justamente, en un conjunto de estereotipos de carácter socio-étnico que han legitimado la extrema explotación a la que se encontraban sujetos los aborígenes de la región. En la lógica de los sectores dominantes de la empresa y la mayoría de la dirigencia política de la provincia, existía - y aún perdura aunque con matices - una asociación explícita entre las fuertes exigencias de trabajo en los ingenios y una resistencia física ("soportabilidad para el trabajo rudo") que sería inherente a grupos de poblaciones concretas, y que se basa precisamente en las categorizaciones socio-étnicas negativas descriptas ya en la pluma de los españoles. Así pues, es en este tipo de asociaciones hegemónicas ligadas a la etnicidad y a los sectores de clases más bajos en donde radica, ahora ya re-significado, el sentido de la dureza o la resistencia corporal ejemplificada bajo diferentes epítetos: "los coyas duros", "chaguancos [mataguayos] salvajes y guerreros".

Tal como nos relata el músico y poeta jujeño Fortunato Ramos (2006), es en la zafra en donde se produce el "encuentro" de estos grupos ("los de arriba") con "los chaguancos y matacos" ("los de abajo"). En efecto, durante las primeras décadas del siglo XX, existió una clara diferenciación por parte de la estructura empresarial de los ingenios para con la mano de obra indígena. Entre las preferencias para contratar mano de obra, se encontraban los matacos, tobas, pilagás y mocovíes. Como lo afirma el inspector del ingenio Vidal: "[...] la de los matacos, principalmente, es la más preferida, pues son más hacendosos, hábiles y útiles y acaso también por su ignorancia que permite explotarlos en sus jornales" (CONTI; TERUEL; LAGOS., 1988, p. I8).

La práctica del fútbol como deporte moderno, y su desarrollo original en los valles orientales de Jujuy, estuvo indudablemente asociada a los ingenios azucareros británicos instalados en la región desde finales del siglo XIX." ' Los diferentes pueblos originarios que, bajo coerción, ocuparon el proceso de trabajo más bajo y peor pago de los ingenios, también aprendieron a jugar al fútbol en su posición de subalternos. Así pues, en las temporadas que se encontraban fuera del trabajo y regresaban a sus hogares en los valles de altura, jugaban al fútbol pero reproduciendo las tensiones micro-locales como parte esencial del juego.

Llegado a este punto, y teniendo en cuenta los antecedentes históricos que relacionan el fútbol con la influencia británica en toda la región ${ }^{22}$, resulta al menos

11. Sobre la relación entre el fútbol como deporte moderno y los operarios ingleses de los ingenios azucareros de Jujuy hacia finales del S. XIX, se puede consultar un trabajo de mi autoría titulado: "De trofeos y Orgullos: Apuntes sociológicos sobre el fútbol y los procesos identitarios en Jujuy (Argentina), en Actas del Primer encuentro de la Asociación Latinoamericana de Estudios Socioculturales del Deporte. Curitiba, Brasil. Año 2008.

12. Para un análisis particular sobre los orígenes del fútbol en Jujuy y sus vínculos con el personal británico en el transporte ferroviario local, puede consultarse el texto de J. P. Ferreiro, E. Blanco y S. Braylovsky (2000) "Identidad y poder en el fútbol: algunas reflexiones a partir de la experiencia jujeña". 
tentador aplicar casi mecánicamente el modelo configuracional de N. Elias sobre los procesos de regulación emocional y progresivo auto-control que devienen en la práctica de los deportes modernos. Sin embargo, existen aquí dos dimensiones de un mismo proceso que complejiza el análisis, y que nos remiten al doble sentido del juego, tal y como lo ha definido originalmente Simmel.

En primer lugar, las relaciones de poder en las que los pueblos originarios se encontraban inmersos al momento de la instalación de los ingenios en la región, tuvo que ser mucho más violenta que los vínculos establecidos entre la elite británica de finales del siglo XVIII para con el pueblo llano ingles, y entre los mismos participantes de las competencias dentro de los círculos de caballeros británicos. En el ámbito estrictamente local, los operarios ingleses seguramente no consideraban a los trabajadores indígenas como portadores de un cuerpo naturalmente "dúctil" y/o "flexible", capaz de captar (aprehender) las reglas de este tipo de prácticas mediante el juego cuerpo a cuerpo.

Una segunda dimensión de este proceso, es decir, de la importación británica del fútbol y sus consecuencias a nivel local, implica el análisis detallado de los enfrentamientos bélicos entre grupos diferentes, y las disputas inter-étnicas a nivel regional que preceden al fútbol como juego. Un ejemplo de este tipo de enfrentamientos en los andes son los denominados tinkus, batallas rituales andinas en donde se produce un choque entre agrupaciones territoriales y sociales en constante diferenciación y conflicto (mitades endogámicas), cuya base primaria ha sido y es, en el caso de Macha (Bolivia), el ayllu. La noción de lucha corporal que se manifiesta en este ritual es un fenómeno complejo que incluye la idea de fuerza y violencia animal en el contexto de una verdadera batalla.

Si bien en el sector norte del actual departamento Valle Grande, hemos encontrado una lógica de comportamiento nupcial que nos remite a ciertas estructuras parentales ya investigadas especialmente para la región sur-andina ${ }^{13}$, no es posible aquí el reconocimiento del ayllu, ya sea como unidad histórica desagregada, o como base sociológica de organización primaria en todo el territorio vallegrandino. En cambio, todos los demás elementos de contenido que animan las batallas rituales como el tinku, pueden ser reconocidas en las disputas futbolísticas de larga tradición histórica en los valles orientales. Así, por ejemplo, en los cotejos futbolísticos vallistos se ponen en juego disputas parentales y territoriales relacionadas con el pastoreo de ganado y las áreas aptas para el cultivo de secano. Antes y durante los choques entre

13. Conjuntamente con el Dr. Juan Pablo Ferreiro hemos encontrado la existencia, durante gran parte del siglo XIX en la región de Valle Grande, de una marcada tendencia hacia la homogamia y la bilocalización de la población vallista, estableciéndose una "lógica" de red relacional matrimonial y parental similar a las ya registradas en la región sur-andina. 
los equipos, se produce una ingesta importante de alcohol en donde participan tanto hombres como mujeres. Asimismo, en gran parte de los jugadores del campeonato vallegrandino con quienes he mantenido diálogos informales y entrevistas grabadas, se visualiza una relación íntima entre el consumo de determinados alimentos y bebidas (carne vacuna asada, maíz molido, vino) como agentes proveedores de una fuerza adicional que puede plasmarse en una forma de juego rudo y resistente; mimetizándose así con las figuras de animales de naturaleza fuerte que con-viven en el entorno ecológico de la región.

En suma, podemos observar entonces dos dimensiones que vinculan los procesos de categorización socio-étnicas ligados fuertemente al cuerpo a lo largo de un proceso histórico de larga duración.

Ahora bien, el hecho de que en la práctica del fútbol vallegrandino se cristalicen, a manera de insulto, epítetos peyorativos y pre-seleccionados basados en "lo étnico" (coyas, matacos, chaguancos), nos muestra una versión ya re-configurada, y con un fuerte anclaje en lo fenotípico-corporal, cuyas raíces se remontan a tiempos pre-hispánicos. Como se señaló, la violencia efectivamente presente en los enfrentamientos entre grupos originarios, fue "traducida", en la lógica euro-céntrica española, a la manera de un salvajismo primigenio e inalterable, cuyas marcas se encontraban "naturalmente" en el cuerpo.

Desde la instalación a finales del siglo XIX de los ingenios azucareros cercanos a Valle Grande, estos estereotipos socio-étnicos sobre los cuerpos vallistos, son re-significados, en el discurso dominante, para dar un "sentido naturalizador" a la explotación en el trabajo que funcionó fundamentalmente hacia afuera de la región vallegrandina, mientras que en la lógica del enfrentamiento deportivo interno (solo entre vallistos) los "rótulos" étnicos y territoriales pueden actuar no solamente como insulto, sino también como símbolo de fuerza viril, por ejemplo, en el razonamiento que afirma que los jugadores vallistos: "son duros y fuertes para el juego porque nacieron y crecieron (se alimentaron) entre los cerros".

La relación entre el sentimiento ambivalente de orgullo expresado por un experimentado jugador de fútbol en los campeonatos vallistos, quizás exprese con mayor nitidez los efectos generados a partir de categorizaciones históricas sedimentadas en biografías emocionales y corporales.

\footnotetext{
"Me acuerdo de un partido donde pasó de todo: empezamos perdiendo, empatamos y después pasamos a ganar. Yo hice dos goles, con uno empezábamos a ganar el partido y la gente de Valle Grande (simpatizantes) me gritaban feo, que vos sos esto, que vos sos lo otro, me insultaban. Yo lloraba, todos se venían contra mí, lloraba de bronca por los gritos, pero seguía jugando" (Fragmento de entrevista B2, con M, 2008).
} 
Según el relato del jugador $M$, las emociones encontradas dentro de un partido de fútbol local pueden variar de un minuto a otro y de manera relativa con las contingencias del juego. Se trata, en suma, del entrecruzamiento entre las identificaciones fuertes de los simpatizantes para con el equipo, y el "poner el cuerpo" en el campo de juego. Actualmente, en la perspectiva exógena al área vallegrandina, y fundamentalmente en el mundo del trabajo urbano, estas mismas adjetivaciones tienden a hiper-concentrarse en una narrativa sobre el cuerpo individual, entendido como un recipiente de energía eficaz para el trabajo manual, mal pago y basado casi exclusivamente en la fuerza física. Así pues, y tal como lo expresa un joven vallisto que migró a finales de los 90' hacia Buenos Aires en busca de trabajo:

(...) Cuando llegas a Buenos Aires la gente te busca, por que ya te mira y sabe que vos sos del norte, entonces prefieren del norte siempre. Será porque que trabajamos y nada más.... Otro capaz que pide más y entonces... Para todo buscan del norte, para cortar un jardín, para lavar (Fragmento de una entrevista abierta con D, localidad de Santa Ana).

\section{CONSIDERACIONES FINALES}

A lo largo de éste artículo he planteado al menos tres grandes líneas de interpretación, surgidas a partir de un cúmulo de información producto del análisis histórico, y el trabajo etnográfico intensivo que desarrollé dentro del área de estudio.

Un primer abordaje de la información socio-histórica centrada en los procesos de categorización e identificación socio-étnica dentro de una macro-región, posibilitó la contextualización de las nociones corporales dominantes y sus vínculos con categorías étnicas re-significadas por la colonización española.

En segundo lugar, vimos como paralelamente con la irrupción de la industria azucarera cercana al departamento Valle Grande, y el consecuente cambio en las formas de trabajo y sujeción a la que estaban sometidos los pueblos originarios vallistos, surge la práctica del fútbol como deporte moderno a través de la influencia británica dentro de la región.

Este último proceso histórico, trajo como consecuencia una nueva configuración de las categorizaciones corporales cargadas de atributos estigmatizantes cuyas bases se remontan a los tiempos hispano-coloniales. Es precisamente en el contexto particular que se dio en este periodo - caracterizado por mecanismos de poder categorial y explotación en manos de quienes contrataban a la fuerza de trabajo indígena -, donde he propuesto situar y re-pensar la aplicación en el ámbito local del análisis planteado por $\mathrm{N}$. Elias en torno a las condiciones históricas que posibilitaron el surgimiento de los deportes modernos en el occidente europeo. 
Por último, he desarrollado un tercer análisis donde la práctica del fútbol ya forma parte de la cotidianidad de los pobladores vallistos, constituyéndose en un espacio donde es posible leer en forma oblicua estas largas historias de categorización e identificación micro y macro-regionales. A diferencia de las anteriores interpretaciones, aquí el fútbol como práctica estrictamente local, permite establecer distinciones entre proceso de adjetivaciones sobre lo corporal y "lo étnico" hacia el interior y al exterior de los pueblos vallistos.

A finales de la década del 90' del siglo XX, bajo un contexto creciente de desempleo y flexibilización laboral, este tipo de categorizaciones y su dinámica interna-externa asumen un entramado particular donde confluyen diferentes campos (el fútbol como deporte, el ámbito laboral, el espacio rural, el espacio urbano). Esta nueva disposición nos introduce necesariamente en una re-ubicación del eje analítico entre campos diferentes pero vinculados históricamente entre sí como lo son: las clasificaciones corporales expresadas a través del fútbol basadas en criterios socio-etnicos, y la segmentación del mercado de trabajo en el presente.

\section{Os corpos e suas marcas socioétnicas: futebol, identidades e história em Valles Leste de Jujuy (Argentina)}

RESUMO: Produto de uma investigação etnográfica desenvolvida durante quatro anos (200720 10) nos vales leste da província de Jujuy (Argentina), este artigo pretende discutir uma série de processos históricos de longa duração em uma área de estudo particular, para estabelecer as coordenadas estruturais que permitiram configurar as relações entre: noções sócio-históricas de corpos, as categorizações socioétnicas regionais dominantes e as identificações de grupo mais profundas entre os jogadores e simpatizantes do futebol praticado entre os povos Vallistos. PALAVRAS-CHAVE: Corpo; etnia; identidades; futebol

The bodies and their socio-ethnic brands: football, identities and history in the Valleys east of Jujuy (Argentina)

ABSTRACT: Product of an ethnographic research developed during four years (2007-2010) in the East valleys of the province of Jujuy (Argentina), this article aims to discuss historical processes in a particular case, in order to establish the structure that allowed to configure relations between: socio-historical notions of "bodies", the dominant regional socio-ethnic categorizations and the deepest identity between players and supporters (hooligans) of football practiced among the "Vallistos" people.

KEY WORDS: Body; ethnicity; identities; football 


\section{REFERENCIAS}

BARTH, F. Los grupos étnicos y sus fronteras. México. Fondo de Cultura Económica, 1976.

CONTI, V.; TERUEL, A.; LAGOS, M. "Mano de obra indígena en los ingenios de Jujuy a principios de siglo" en conflictos y procesos en la historia Argentina contemporánea. Buenos Aires: Centro de Editores de América Latina, 1988.

ELIAS N.; DUNNING E. Deporte y ocio en el proceso de la civilización. México: Fondo de Cultura Económica, 1992

ELIAS NORBERT. Sociología fundamental. Barcelona: Gedisa, 1982.

FEO, C.; FERNÁNDEZ, A. "Una aproximación al periodo Tardío en la arqueología de Valle Grande (Jujuy)" en Pasado y Presente de un mundo postergado. JEREZ, O. (Ed.). San Salvador de Jujuy. Universidad Nacional de Jujuy, 1998.

FERNÁNDEZ, F. De trofeos y orgullos: apuntes sociológicos sobre el fútbol y los procesos identitarios en Jujuy (Argentina). In: ENCUENTRO DE LA ASOCIACIÓN LATINOAMERICANA DE ESTUDIOS SOCIOCULTURALES DEL DEPORTE, I., Curitiba, 2008. Actas... Curitiba, 2008.

FERREIRO, J. P., BRAYLOVSKY, S.; BLANCO, E. Identidad y poder en el fútbol: algunas reflexiones a partir de la experiencia jujeña. In: ALABARCES, P. Peligro de gol: estudio sobre deporte y sociedad en América Latina. Buenos Aires: Editorial CLACSO, 2000.

FERREIRO, J. P. Del oficio de la memoria. San Salvador de Jujuy. Revista Cultural: el duende, 1997.

FERREIRO, J. P. El Chaco en los Andes: churumatas, paypayas, yalas y ocloyas en la etnografía del oriente jujeño. Población y Sociedad, Tucumán, n. 2, 1994.

FUMAGALLI, M. Vinculaciones transversales en el periodo de desarrollo regionales entre los valles orientales y el sector meridional de la Quebrada de Humahuaca. Cuadernos, San Salvador de Jujuy, 5, 1995.

KARASIC, G. La etnografía en el cuerpo: dominación e insumisión en las exploraciones de principios del siglo XX en Jujuy (Argentina). Revista Pacarinas, Jujuy, 2003.

LE BRETON, D. Antropología del cuerpo y modernidad. Buenos Aires: Nueva Visión, 2002.

LE BRETON, D. La sociología del cuerpo. Buenos Aires: Nueva Visión, 2002.

LOZANO PEDRO. Descripción corográfica del Gran Chaco Gualamba. Tucumán: Ed. da Universidad Nacional de Tucumán, [1733] 1989.

MAUSS MARCEL. Sociología y antropología. Buenos Aires: Tecnos, 1979 
MÉTRAUX, A. Warfare, cannibalism, and human trophies: In: STEWARD, J. H. (Ed.) Handbook of South American Indians. Washington: States Government Printing Office, 1949.

RAMOS, F. El colla, sus costumbres, sus paisajes, su cultura. Humahuaca: Jujuy, 2006.

RUTLEDGE I. Cambio agrario e integración: el desarrollo del capitalismo en Jujuy: 1550 - 1960. Buenos Aires: Edit. MLAL, 1987.

SIMMEL, G. Cuestiones fundamentales de sociología. Barcelona. Edit. Gedisa, 2003.

Recebido em: 22 ago. 201 I

Aprovado em: 17 out. 2011.

Endereço para correspondência:

Calle Alferez Sobral N²776

Barrio San Pedrito

San Salvador de Jujuy. Provincia de Jujuy (Argentina)

CP. 4600 